\title{
Analysis of Non-Pharmaceutical Interventions Impacts on COVID-19 Pandemic in Iran
}

\section{Sara Saadatmand}

Persian Gulf University

Khodakaram Salimifard ( $\nabla$ salimifard@pgu.ac.ir )

Persian Gulf University https://orcid.org/0000-0002-7059-724X

\section{Reza Mohammadi}

University of Amsterdam: Universiteit van Amsterdam

\section{Research Article}

Keywords: COVID-19, pandemic modeling, SEIR model, nonpharmaceutical interventions, nonlinear dynamics

Posted Date: March 1st, 2021

DOl: https://doi.org/10.21203/rs.3.rs-211369/v1

License: (9) This work is licensed under a Creative Commons Attribution 4.0 International License. Read Full License

Version of Record: A version of this preprint was published at Nonlinear Dynamics on January 11th, 2022. See the published version at https://doi.org/10.1007/s11071-021-07121-8. 


\title{
Analysis of Non-pharmaceutical Interventions Impacts on COVID-19 Pandemic in Iran
}

\author{
Sara Saadatmand \\ CIIORG, Persian Gulf University, Bushehr, 75169, Iran \\ sara.saadatmand@mehr.pgu.ac.ir \\ Khodakaram Salimifard (corresponding author) \\ CIIORG, Persian Gulf University, Bushehr, 75169, Iran \\ salimifard@pgu.ac.ir \\ Tel: (+98) 7731222118 \\ Reza Mohammadi \\ Department of Operation Management, Amsterdam Business School, University of \\ Amsterdam, Netherlands
}

\begin{abstract}
The COVID-19 pandemic has had a huge impact on people's health, and countries' infrastructures around the globe. Iran was one of the first countries that experienced the vast prevalence of the coronavirus outbreak. Iranian government applied various nonpharmaceutical interventions to eradicate the epidemic in different periods. To evaluate the effectiveness of applied policies, the number of cases and death before and after the interventions studied and the effective reproduction number of the infection was analyzed under various scenarios. The SEIR generic model was applied to capture the dynamic of the pandemic in Iran. It is assumed that changes in reproduction number are responses to interventions. Depending on how responsive people to the government interventions, the effectiveness of each intervention has been investigated. Based on the model results, the peak of the total number of infected individuals will occur around the end of May and the start of June 2021. It is revealed that the outbreak had been able to be smoothed if the government had continued the full lockdown and strict quarantine. The result will allow for the assessment of the effects of different government interventions in new outbreaks.
\end{abstract}

Keywords: COVID-19, pandemic modeling, SEIR model, nonpharmaceutical interventions, nonlinear dynamics 


\section{Introduction}

Epidemic diseases have always been a threat to human life. Some of them are prevalent throughout various continents and countries and become pandemic. Black Death and 1918 influenza pandemic are among the deadliest pandemics in human life and caused millions of death in past centuries [1]. Except for its influence on humans' fatality, the epidemic can have irreparable losses in nations' economics and industries. Among recent epidemic illnesses such as Ebola, yellow fever and Zika the novel coronavirus has attracted a lot of attention due to its infections and death numbers. The novel Coronavirus (COVID-19) is a new type of coronaviruses family that can cause different diseases, which are frequently respiratory infections. The severity of illnesses can vary from common cold to the Middle East respiratory syndrome (MERS) and, severe acute respiratory syndrome (SARS)[2]. This virus first appeared in Wuhan, Hubei province of China on December 29th, 2019 and then spread rapidly across the world. On March 11th, 2020, the World Health Organization (WHO) characterized this illness as a pandemic [3].

The COVID-19 epidemic has had a huge impact on people's health, economics and countries' infrastructures such as communication, transportation, energy, and public health and due to that the government have applied rigid health interventions to reduce its impacts. Health interventions refer to those activities and actions, which protect human health and mitigate the disease prevalence, by decreasing disease duration and severity, and function lost [4]. One of the classifications for health interventions is to divide them into two classes of pharmaceutical and non-pharmaceutical interventions. The first class contains vaccines and antiviral drugs [5] and the second one includes government interventions like postpone and cancel the events, social distancing, travel restrictions, and, home quarantine [6].

Lockdown is among the non-pharmaceutical interventions used vastly in most of the countries in different periods of times to control the virus spread. The main goal of this strategy is to decrease the number of infected individuals so the hospital overcapacity that causes more deaths would be prevented. Merriam-Webster dictionary defines lockdown as a situation that is not permanent and apply by governmental authorities in time of epidemic to make people stay home and limit the outside activities [7]. Full and partial lockdown are two common lockdown strategies imposed by government on communities around the world to reduce the effect of the pandemic. During the COVID-19 outbreak, several countries such as China, Italy, Spain, and France applied strict complete lockdown while Singapore, Russia, and Morocco used partial lockdown in which some of the social and economic activities were allowed [8]. 
Analysis and predict the behavior of viruses in a community is a vital issue to provide a comprehensive view for policymakers and assist them in making decisions for interventions such as lockdown and vaccine. Mathematical compartmental modeling is a quantitative approach that is based on the system of differential equations that capture the dynamic of epidemic transmission [9]. SIR (susceptible-infective-recovered) model is one of the most used epidemic compartmental models [10] especially to study the COVID-19 prevalence [11]. By presenting two parameters, this model proposes a more clear and understandable tool in comparison to its more complex derivatives[12]. Mathematical SIR models have been used in many articles so far to make predictions about the novel Coronavirus and evaluate authorities' interventions. Malavika et.al [13] applied this model to estimate the number of infected cases and predict the time of pick in India. They couldn't find any evidence that proves the relationship between reducing the number of infected persons and applying lockdown. [14] Used SIR and machine learning modeling to forecast the pandemic behavior in the next 700 days under three scenarios: no actions, lockdown, and new medicines in KSA. The results indicated that containment strategies such as lockdown and quarantine alone are inadequate to eradicate the pandemic.

To predict the number of cases and the second wave of epidemic in Iran Ghanbari [15] developed a SIR model with two compartments for infected people : $I_{1}(t)$ (infected individuals with strong immunity system), and $I_{2}(t)$ (infected individuals with weak immunity system). The results revealed that the second wave in Iran would be more intense than the previous one. Tutsoy et.al [16] extended a new model from SIR called SpID to forecast fatality in Turkey. [17] Used a modified SIR model with global pandemic data to predict the virus spread globally with considering environmental factors like temperature and humidity. To predict the epidemic trend in Italy Wangping et.al [18] applied an extended SIR model to the time series data. [19] Estimated the basic reproduction number $\left(R_{0}\right)$ by using the compartmental SIR model in India. To evaluate the amount of infected population and deaths in Sweden Qi et.al [20] applied SI, SIR, and SID epidemic models.

Among SIR extensions the classical SEIR is one of the most traditional epidemic model which indicates the progression of virus in population by four states: Susceptible(s), Exposed (E), Infectious (I), and Recovered (R)[21]. This model has been used in several articles to predict and evaluate the spread of novel coronavirus pandemic. Kwuimy et.al. [22] used a nonlinear SEIR model to analyze the dynamic behavior of the COVID-19 pandemic in South Korea. The genetic algorithm were applied to approximate the model parameters. [21] Studied the 
management strategies such as lockdown with adaption of SEIR model in the US. To forecast the COVID-19 evaluation in Hubei province [23] applied an extended SEIR model with quarantine and hospitalized compartments under different scenarios and the particle swarm optimization (PSO) algorithm to estimate the model parameters. [24] proposed a new SEIR model with two more components: quarantined and insusceptible. Their improved model captured the prevalence of the virus in the US and forecasted the future trend. Jayrold et al. [25] Used the extension of SEIR to estimate the effective reproduction number for several countries. [26] Developed a SEIR model with the effect of time delay for India. Arghya et al. [27] applied SEIR epidemiological model to predict the peak of infected cases and explore the impact of social distancing and testing-quarantining on virus propagation.

Iran was one of the first countries which experienced the vast spread of this virus. The first confirmed cases in Iran were reported on February 19, 2020 in city of Qom [28]. Since then, the Iranian government have used several policies and strategies based on a number of confirmed cases and death in provinces. According to the confirmed cases statistics, each city is categorized in one of the blue, yellow, orange, and red categories which sequence demonstrates the severity of the pandemic from low to high. Based on literature, no article has evaluated the effectiveness of government interventions on COVID-19 prevalence in Iran.

In the following first the epidemic SEIR model will be described, then the impact of lockdown on number of infected individuals, and deaths will be evaluated. Then, based on the official reported data the parameters will be estimated and the model will forecast the next peak of outbreak in Iran. Finally, the conclusion will be presented.

\section{Epidemic Modeling}

The advent and outbreak of epidemic has always been a noticeable issue in mathematical modeling in order to predict the virus spread and evaluate the impact of policies and interventions. Mathematical epidemic models are vigorous tools that let healthcare policy makers anticipate various changes that occur by virus mutation, vaccination, quarantine and lockdown in the number of infected individuals and mortality moreover, make efficient decisions. The first epidemic model was proposed by Daniel Bernoulli (1700-1782) to oppose smallpox, which was one of the fatal diseases in that era. Soon after that different people start to develop epidemic models and finally Kermack and McKendrick presented their compartmental model, which divided the population into three categories: S, I, R [29]. 
Compartmental models simulate the spread of pathogens and investigate the transmission dynamics of contagious disease in a host population[30]. They place population into distinctive classes and people move among them with diverse rates. The model that had been presented by [31] is considered as the basic model in epidemic which later various compartments such as exposed, deceased, and asymptotic were added to it.

\subsection{The SEIR Model}

In the basic model which was introduced by Kermack and McKendrick [31] the host population divided into three classes: susceptible, infected, and recovered that are called S, I, and R in contractions. As shown in Figure 1, the SEIR model adds another component to SIR, which is E and refers to the exposed population. Susceptible are those who have not had the disease before but are likely to get it and are transmitted to E as soon as they are infected. Exposed individuals are who have contracted the virus but are not yet infectious and can transmit it to susceptible. Infected are people who have the disease and the same as the exposed can transmit it to susceptible. The time period that people are in infected class is assumed as the infectious period. Recovered are those who got the disease and got well and have immunity to the virus or died. Eq. (1) denotes the total population and its compartments at time $t$.

$$
N=S(t)+E(t)+I(t)+R(t)
$$

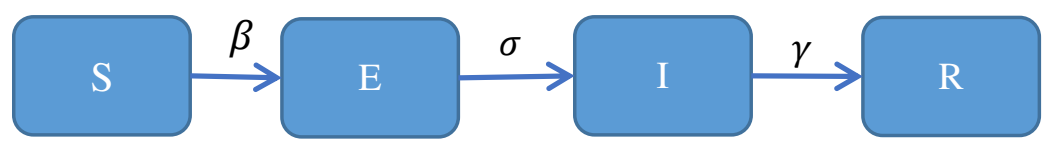

Figure 1: The generic SEIR model.

The SEIR model by applying a system of ordinary differential equations (ODE), presents a constant model with continuous time that has three rates: $\beta, \sigma$ and $\gamma$. The assumption of constant population and model ODEs are shown in Eq. (2) and Eq. (3) respectively. $\beta$ is the transmission rate from susceptible to exposed and called the infection rate. The incubation rate, $\sigma$ is the rate of latent individuals becoming infectious and $\gamma$ is the transition rate from infected to recovered and called recovery rate. All of these parameters are constant.

$$
\frac{d N}{d t}=\frac{d S}{d t}+\frac{d E}{d t}+\frac{d I}{d t}+\frac{d R}{d t} \equiv 0
$$




$$
\left\{\begin{array}{c}
\frac{d S}{d t}=-\frac{\beta I S}{N} \\
\frac{d E}{d t}=\frac{\beta I S}{N}-\sigma E \\
\frac{d I}{d t}=\sigma E-\gamma I \\
\frac{d R}{d t}=\gamma I
\end{array}\right.
$$

\subsection{The basic reproduction number}

$R_{0}$ is the basic reproduction number which is defined as the expected number of secondary cases produced by a single (typical) infection in a completely susceptible population, Eq. (4). It is important to note that $R_{0}$ is a dimensionless number and not a rate, which would have units of time-1. The most important uses of $R_{0}$ are determining if an emerging infectious disease can spread in a population and determining what proportion of the population should be immunized through vaccination to eradicate a disease. In mathematical infection models, when $R_{0}>1$ the infection will spread among the population, but not if $R_{0}<1$. Generally, the larger the value of $R_{0}$, the harder it is to control the epidemic.

$$
R_{0}=\frac{\beta}{\gamma}
$$

\section{Model fitting and parameter estimation}

To make proper estimation of parameters of describing the ODE system the residual sum of squares (RSS) method has been used, as defined in Eq. (5). The residual sum of squares measures the discrepancy between the actual data and the predicted value. Smaller the discrepancy, represents the better parameter estimation.

$$
R S S(\beta, \gamma)=\sum_{t}(I(t)-\tilde{I}(t))^{\wedge} 2
$$

Where I denotes the reported values of infected cases and $I$ is the calculated values of these parameters applying ODE [32]. Figure 2 demonstrates the fitted model against actuals data. To fit the model, the official reported data were applied from "coronavirus" package in $\mathrm{R}$ which uses the raw data pulled from the Johns Hopkins University [33]. 


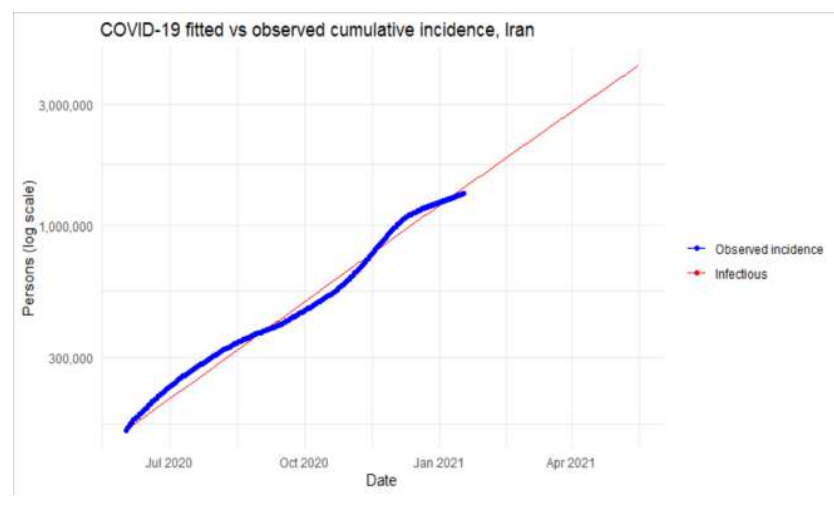

Figure 2 fitted model

\subsection{Prediction the peak of infected individuals}

As it is illustrated in Figure 3, Iran has passed three waves of the outbreak which happened in April, mid-July to mid-September, and December 2020. The speed and severity of the waves have been increasing as the days passed. As shown in Figure 3, and compared to the interval between the first and the second waves, the time interval between the second and the third waves has been reduced.

In this section, the SEIR model is applied to predict the peak of the total number of infected individuals in Iran. The available data from August to January 2020 used to predict the next 6 months.

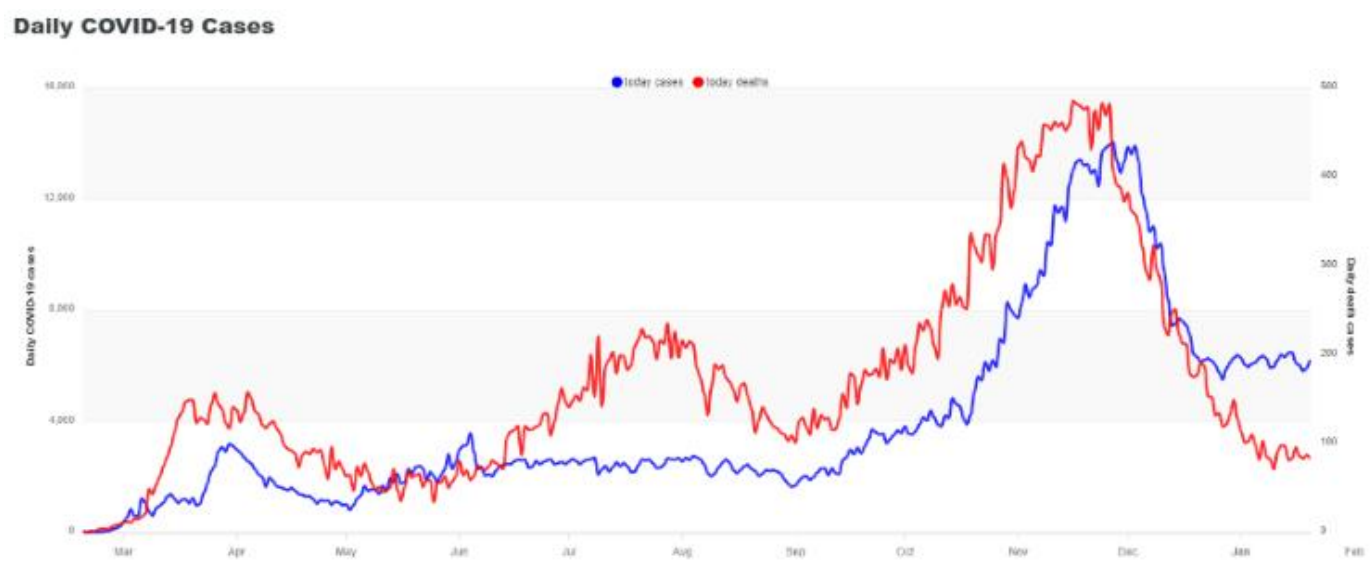

Figure 3: Daily COVID-19 cases and death of Iran

Figure 4 illustrates the number of cumulative predicted infected population according to the reported statistics. Based on the model prediction the peak of the total number of infected population will occur around the end of May and start of June 2021, which the number of cases will gradually grow. To make the curve flatten, government could use interventions to reduce the number of cases and make it close to the threshold of hospital beds. By doing this, hospital 
over-admission could be avoided resulting in a decrease in the health staff workload. Despite of the other countries, Iran has not declared any specific program to vaccinate the population, so it is vital to make proper prediction of the total number of infected people and make effective decisions to fight against the pandemic.

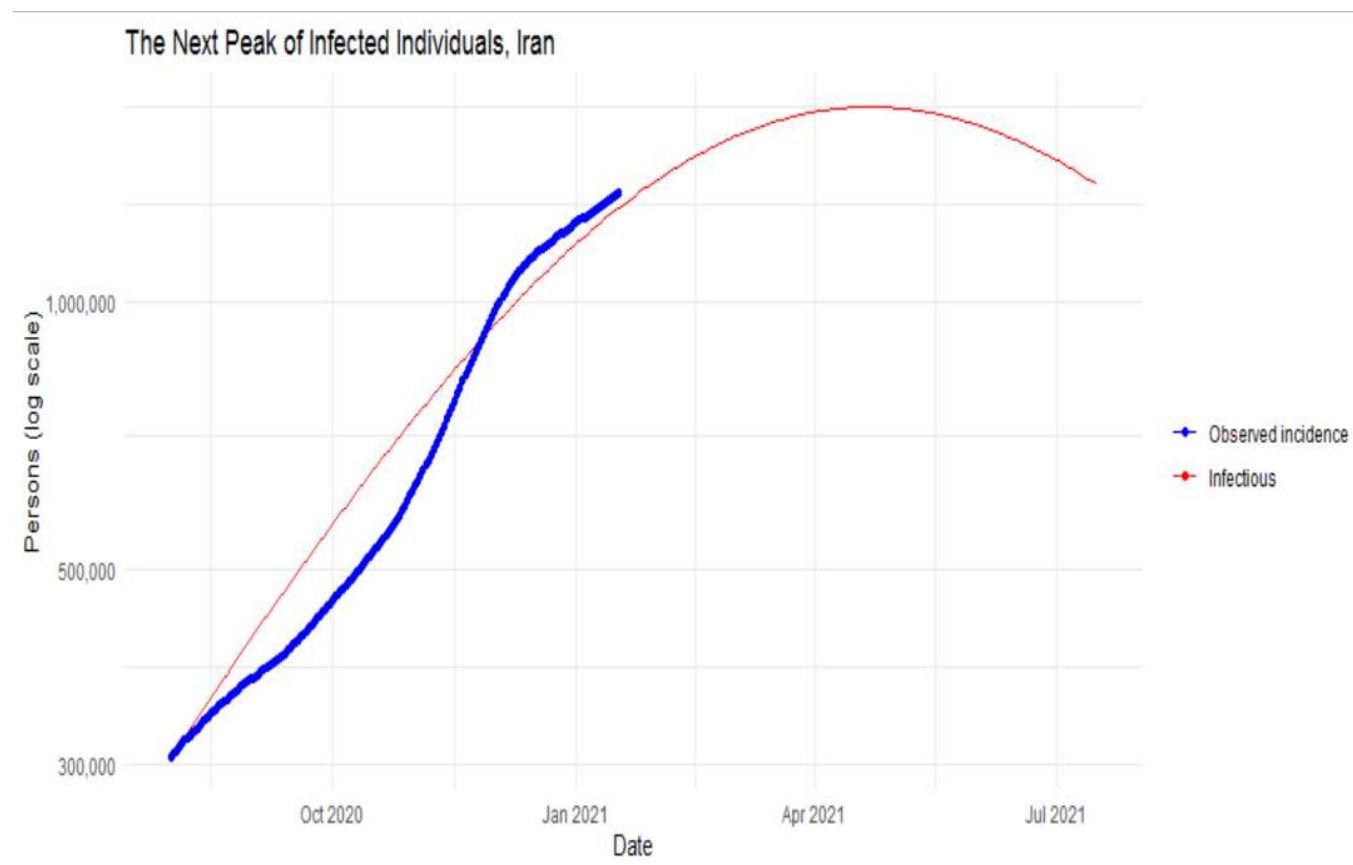

Figure 4: Prediction the next peak

\section{Analysis and results}

The results and analysis of the model will be presented in the following section. First, the effectiveness of lockdown and its impact based on the official reported statistics will be described, then the evolution of the epidemic will be discussed.

\subsection{Impact of lockdown}

Nowruz holiday lockdown was the first intervention to fight against pandemic in Iran. This intervention, which applied on March $20^{\text {th }} 2020$, included travel restrictions and closing welfare and recreational services for 14 days. Figure 5 illustrates the impact of this policy on the number of infected and mortality. It is assumed that the result of interventions appears about two weeks later so 14 days before and after each intervention is considered to observe and evaluate the result more efficiently. The lockdown applied from day 59 until the end of day 73. 
As it is shown in Figure 5 the number of confirmed individuals reached their peak on day 69 which was 3186 and after that, the effect of lockdown appeared and it started to decrease. The amount of mortality follows the same pattern. After this wave government offices, markets and stores were opened. On July the $5^{\text {th }}$, the COVID-19 policy initiative committee made the use of masks mandatory in offices, businesses, and crowded places.

The second lockdown was announce on October $3^{\text {rd }}$ for one week in seven provinces in red condition. Figure 6 demonstrates the changes before, after and during this policy. According to the number of cases and deaths, this intervention has not made any significant difference and just kept the growth rate constant and after about 10 days the number of daily confirmed cases started to grow. About 17 days later on October $26^{\text {th }}$, the third intervention were applied to red cities from day 279 to day 286 for one week and the activities of the three business categories and occupational groups were limited. As it is shown in Figure 7 this strategy could not reduce the infectious and death rate and the number of cases increased rapidly and passed 13000 in one day and for deaths reached 480.

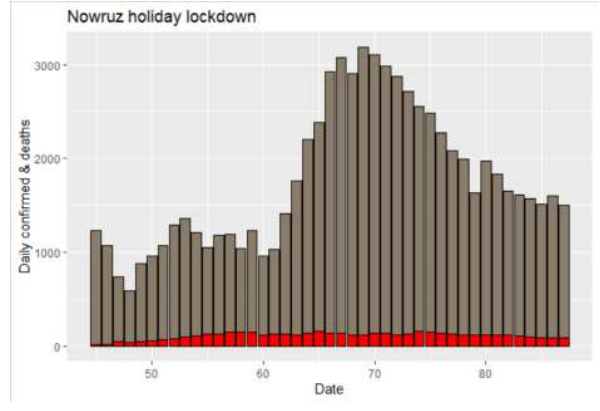

Figure 5 Nowruz holiday lockdown

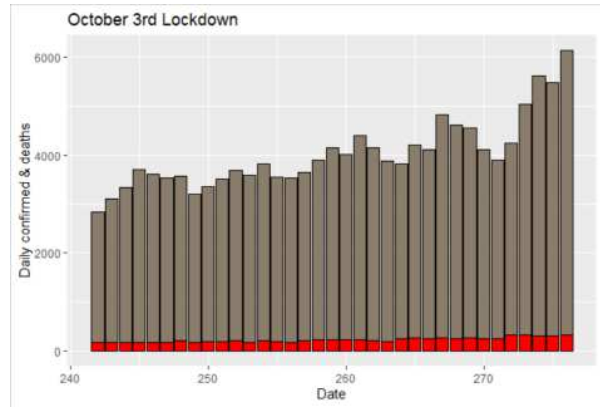

Figure 6 October 3rd Lockdown

Since the previous interventions were not effective and the number of hospitalization were increasing speedily the authorities decided to use stricter interventions. From the start of November $21^{\text {st }}$, travel to and from red cities were banned and vehicles were not allowed to pass after 9 p.m. Figure 8 illustrates the impact of this strategy. After two weeks, the intervention showed its effectiveness and the number of cases and deaths started to decline steadily. Based on all four figures Iran has passed three waves so far which the third one was the deadliest. According to the cases and death figures, Iran reported only the number of critical and hospitalized cases because the pick of deaths and cases is the same, but in theory, the pick of death should be one or two weeks after the pick of infected person. 


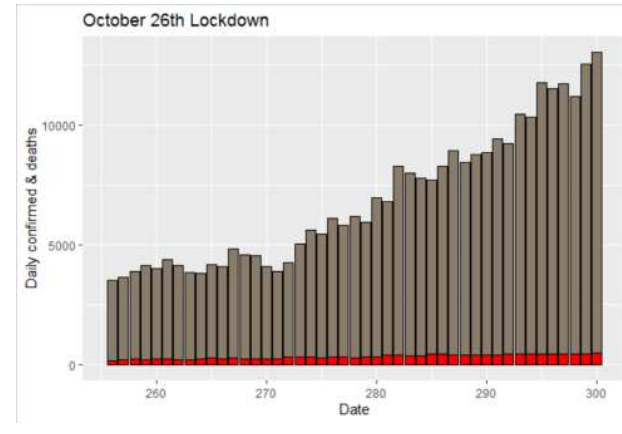

Figure 7 October 26th Lockdown

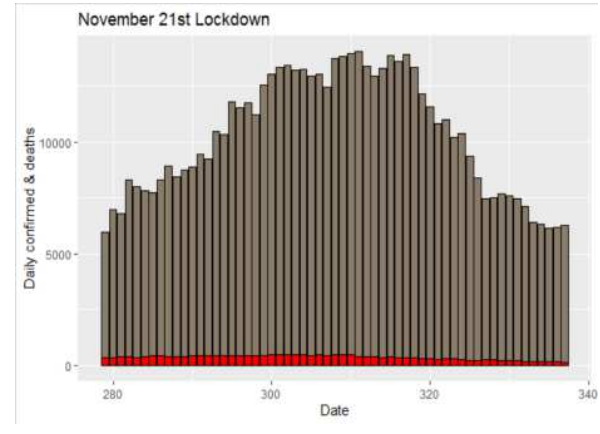

Figure 8 November 21st Lockdown

\subsection{Impact of interventions on R0}

The basic reproduction number $\left(R_{0}\right)$ denotes the number of individuals that can be infected by an infected person. $R_{0}$ is not affected only by viral characteristics but also by environmental conditions or in the case of COVID-19 by people contact rate. This makes it an important factor in evaluating polices and government' interventions in dealing with the current pandemic situation. Intervention strategies such as lockdown have a direct impact on people contact rate which can reduce the number of infected cases. Figure 9 illustrates the estimated number of cases for Iran during the first 90 days of epidemic under various $R_{0}$. As it is shown, the higher rates of $R_{0}$ increase the number of cases exponentially. When the value of $R_{0}$ becomes greater than three the number of infected people grows dramatically.

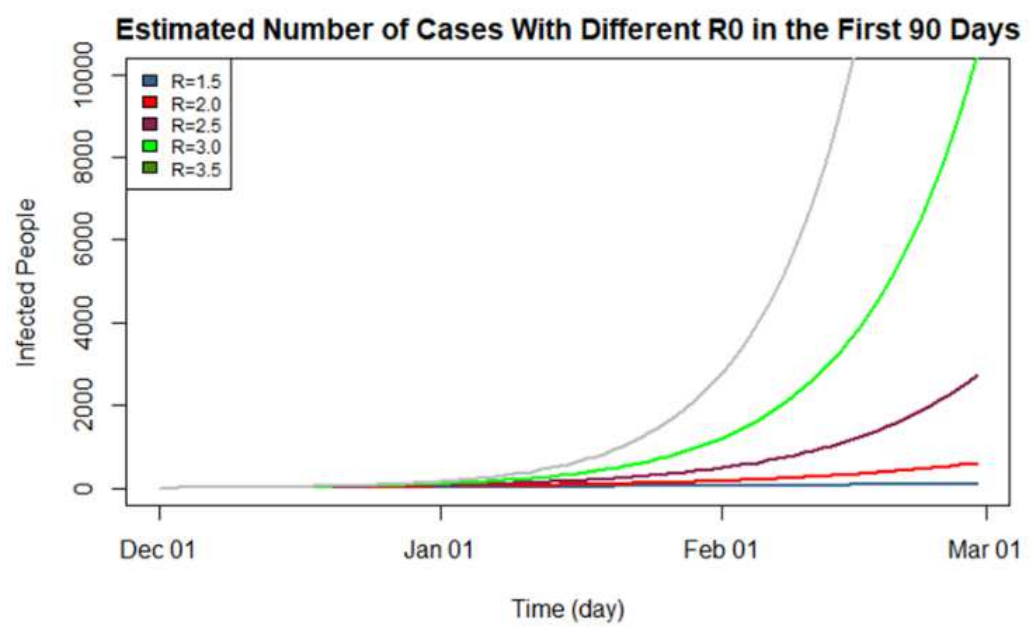

Figure 9: estimated number of cases with different R0

To estimate the impact of various intervention policies on the number of infected people in Iran, two scenarios have been considered. In the first one, it is assumed that the number of exposed people is ten times the number of infected people. In the second one the number of exposed people is set to be 20 times the number of cases. 


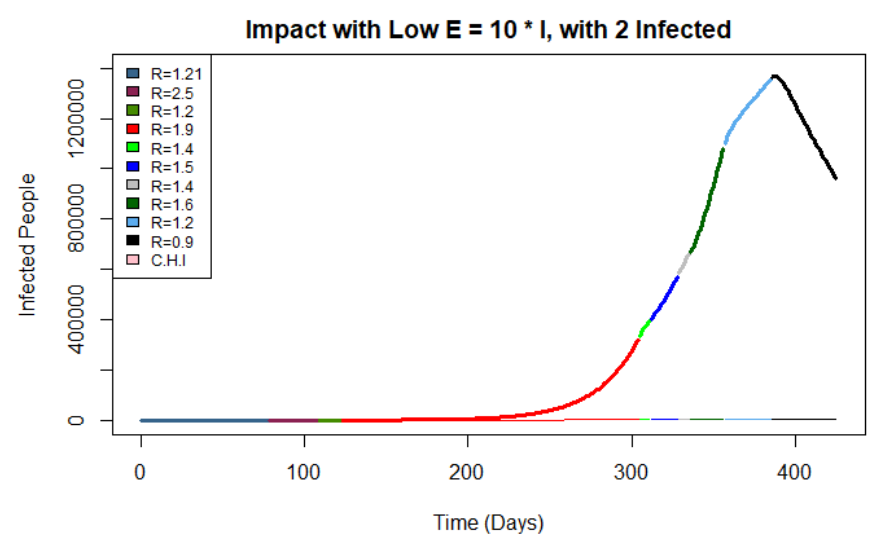

Figure 10: Impact of government interventions under the Low $E$ assumption.

Figure 10 demonstrates the number of infected population in the first scenario with low number of exposed and Figure 11 displays the number sick people with high number of exposed in the second scenario. The effect of government interventions on the number of cases from the beginning of the pandemic is shown with different $R_{0}$ in Figure 10 and Figure 11. In the first scenario with high exposed rate, the number of infected people in the peak is more than 1200000 while in the second scenario with the higher rate of exposed people, it reached to just under 2500000. The Nowruz holiday lockdown was the first hard intervention with $R_{0}=1.2$. The line below the curves indicates the impact of this policy on the amount of infected people if government had decided to continue the policy. In reality, in spite of its great impact on the number of cases, this policy caused a lot of economic issues so policy makers decided to cancel it and limited their interventions to those cities which were in red condition. Because of an early release of all the restrictions, this intervention was not as effective as it was expected, resulting in a sharp increase on the number of people being infected.

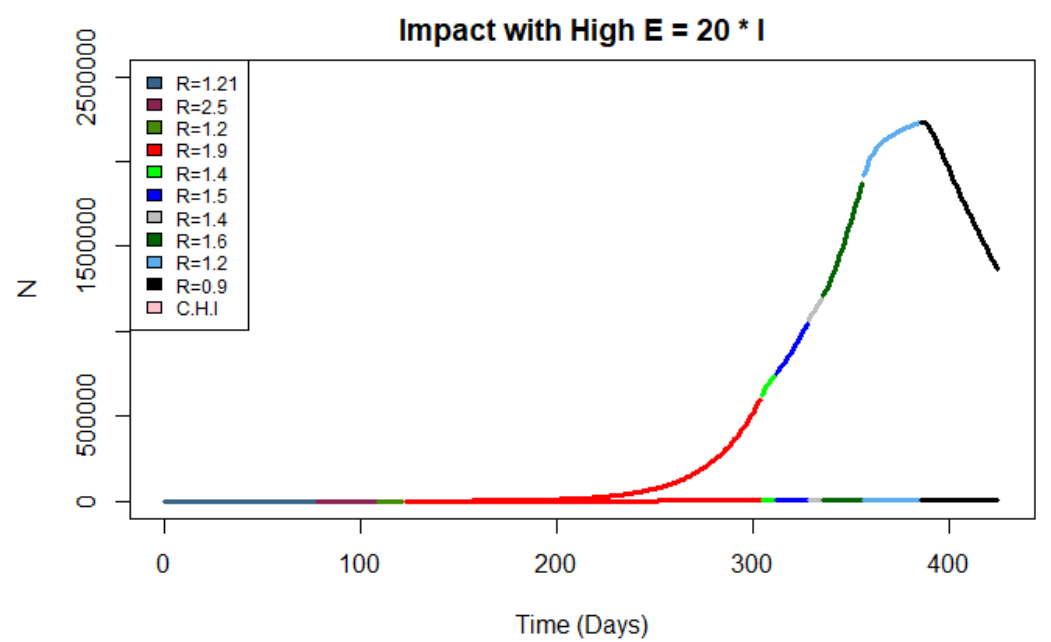

Figure 11: Impact of government interventions under the High E assumption. 


\section{Conclusion}

In this paper the impact of non-pharmaceutical interventions on the number of death and infected people in Iran was evaluated. Since the beginning of the pandemic, Iranian government applied various policies to control the epidemic. The Nowruz lockdown intervention was one of the strictest interventions which lead to economic issues and after that government decided to limit their policy to cities with high rate of infection. This intervention approach increased the amount of cases and caused a high peak of the number of infected people and death. In addition, the basic reproduction number which is an important factor in evaluating the policies and controlling the spread of a virus was analyzed with low and high number of exposed individuals. To predict the peak of the number of infected people, the mathematical SEIR model was used. The official reported data applied to estimate the model parameters. The prediction revealed that the peak of infected population will occur around the end of May and start of June 2021, therefore, we suggest to the officials to consider proper policies to reduce this number and avoid hospital over-admissions.

\section{Funding}

This research has been funded by the National Institute of Genetic Engineering and Biotechnology (NIGEB) of Iran under grant number 99-S-ZH-392.

\section{Conflict of interests}

The authors declare that they have no conflict of interest.

\section{References}

[1] A. Erkoreka, "[Epidemics in nortthern Basque: black death and the Spanish influenza].," Hist. Sci. Med., vol. 42, no. 2, pp. 113-22, [Online]. Available: http://www.ncbi.nlm.nih.gov/pubmed/19230312.

[2] H. Ouassou et al., "The Pathogenesis of Coronavirus Disease 2019 (COVID-19): Evaluation and Prevention," J. Immunol. Res., vol. 2020, pp. 1-7, Jul. 2020, doi: $10.1155 / 2020 / 1357983$.

[3] WHO, "WHO Director-General's opening remarks at the media briefing on COVID-19 11 March 2020," WHO, 2020. https://www.who.int/dg/speeches/detail/who-directorgeneral-s-opening-remarks-at-the-media-briefing-on-covid-19---11-march-2020.

[4] E. Smith PG, Morrow RH, Ross DA, "Types of intervention and their development," in Field Trials of Health Interventions: A Toolbox., 3rd editio., Oxford (UK): OUP Oxford, 2015.

[5] F. G. Yáñez, Andrea, Conor Hayes, "Towards the Control of Epidemic Spread: Designing Reinforcement Learning Environments," AICS, pp. 188-199, 2019.

[6] S. H. Ebrahim, Q. A. Ahmed, E. Gozzer, P. Schlagenhauf, and Z. A. Memish, "Covid-19 
and community mitigation strategies in a pandemic," BMJ, p. m1066, Mar. 2020, doi: 10.1136/bmj.m1066.

[7] Merriam-Webster, "lockdown," 2021.2 https://www.merriamwebster.com/dictionary/lockdown (accessed Jan. 20, 2021).

[8] F. A. H. Jehan Al Humaid, Soban Qadir Khan, Faraz Ahmed Farooqi, Muhanad Alhareky, Faisal Alonaizan, "COVID-19: Impact of early decision and type of lockdown over the spread of the virus," 2020. [Online]. Available: https://www.researchsquare.com/article/rs-26573/v1.

[9] T. Sardar, S. S. Nadim, S. Rana, and J. Chattopadhyay, "Assessment of lockdown effect in some states and overall India: A predictive mathematical study on COVID-19 outbreak," Chaos, Solitons \& Fractals, vol. 139, p. 110078, Oct. 2020, doi: 10.1016/j.chaos.2020.110078.

[10] G. Giordano et al., "Modelling the COVID-19 epidemic and implementation of population-wide interventions in Italy," Nat. Med., vol. 26, no. 6, pp. 855-860, Jun. 2020, doi: 10.1038/s41591-020-0883-7.

[11] M. Liu, R. Thomadsen, and S. Yao, "Forecasting the spread of COVID-19 under different reopening strategies," Sci. Rep., vol. 10, no. 1, p. 20367, Dec. 2020, doi: 10.1038/s41598-020-77292-8.

[12] N. A. Kudryashov, M. A. Chmykhov, and M. Vigdorowitsch, "Analytical features of the SIR model and their applications to COVID-19," Appl. Math. Model., vol. 90, pp. 466473, Feb. 2021, doi: 10.1016/j.apm.2020.08.057.

[13] B. Malavika, S. Marimuthu, M. Joy, A. Nadaraj, E. S. Asirvatham, and L. Jeyaseelan, "Forecasting COVID-19 epidemic in India and high incidence states using SIR and logistic growth models," Clin. Epidemiol. Glob. Heal., vol. 9, pp. 26-33, Jan. 2021, doi: 10.1016/j.cegh.2020.06.006.

[14] S. A. Alanazi, M. M. Kamruzzaman, M. Alruwaili, N. Alshammari, S. A. Alqahtani, and A. Karime, "Measuring and Preventing COVID-19 Using the SIR Model and Machine Learning in Smart Health Care," J. Healthc. Eng., vol. 2020, pp. 1-12, Nov. 2020, doi: $10.1155 / 2020 / 8857346$.

[15] B. Ghanbari, "On forecasting the spread of the COVID-19 in Iran: The second wave," Chaos, Solitons \& Fractals, vol. 140, p. 110176, Nov. 2020, doi: 10.1016/j.chaos.2020.110176.

[16] O. Tutsoy, S. Colak, A. Polat, and K. Balikci, "A Novel Parametric Model for the Prediction and Analysis of the COVID-19 Casualties," IEEE Access, vol. 8, pp. 193898193906, 2020, doi: 10.1109/ACCESS.2020.3033146.

[17] J. Huang et al., "Global prediction system for COVID-19 pandemic," Sci. Bull., vol. 65, no. 22, pp. 1884-1887, Nov. 2020, doi: 10.1016/j.scib.2020.08.002.

[18] J. Wangping et al., "Extended SIR Prediction of the Epidemics Trend of COVID-19 in Italy and Compared With Hunan, China," Front. Med., vol. 7, May 2020, doi: 10.3389/fmed.2020.00169.

[19] S. Das, "Prediction of COVID-19 Disease Progression in India: Under the Effect of National Lockdown," Apr. 2020, [Online]. Available: http://arxiv.org/abs/2004.03147.

[20] C. Qi, D. Karlsson, K. Sallmen, and R. Wyss, "Model studies on the COVID-19 pandemic in Sweden," Apr. 2020, [Online]. Available: http://arxiv.org/abs/2004.01575.

[21] A. Rădulescu, C. Williams, and K. Cavanagh, "Management strategies in a SEIR-type model of COVID 19 community spread," Sci. Rep., vol. 10, no. 1, p. 21256, Dec. 2020, doi: 10.1038/s41598-020-77628-4. 
[22] C. A. K. Kwuimy, F. Nazari, X. Jiao, P. Rohani, and C. Nataraj, "Nonlinear dynamic analysis of an epidemiological model for COVID-19 including public behavior and government action," Nonlinear Dyn., vol. 101, no. 3, pp. 1545-1559, Aug. 2020, doi: 10.1007/s11071-020-05815-z.

[23] S. He, Y. Peng, and K. Sun, "SEIR modeling of the COVID-19 and its dynamics," Nonlinear Dyn., vol. 101, no. 3, pp. 1667-1680, Aug. 2020, doi: 10.1007/s11071-020-05743-y.

[24] C. Xu, Y. Yu, Y. Chen, and Z. Lu, "Forecast analysis of the epidemics trend of COVID-19 in the USA by a generalized fractional-order SEIR model," Nonlinear Dyn., vol. 101, no. 3, pp. 1621-1634, Aug. 2020, doi: 10.1007/s11071-020-05946-3.

[25] J. P. Arcede, R. L. Caga-anan, C. Q. Mentuda, and Y. Mammeri, "Accounting for symptomatic and asymptomatic in a SEIR-type model of COVID-19," Math. Model. Nat. Phenom., vol. 15, p. 34, Jun. 2020, doi: 10.1051/mmnp/2020021.

[26] M. Radha and S. Balamuralitharan, "A study on COVID-19 transmission dynamics: stability analysis of SEIR model with Hopf bifurcation for effect of time delay," Adv. Differ. Equations, vol. 2020, no. 1, p. 523, Dec. 2020, doi: 10.1186/s13662-020-029586.

[27] A. Das, A. Dhar, S. Goyal, A. Kundu, and S. Pandey, "COVID-19: Analytic results for a modified SEIR model and comparison of different intervention strategies," May 2020, doi: 10.1016/j.chaos.2020.110595.

[28] Wikipedia, "COVID-19 pandemic in Iran," 2020. https://en.wikipedia.org/wiki/COVID19_pandemic_in_Iran.

[29] F. Brauer, "Mathematical epidemiology: Past, present, and future," Infect. Dis. Model., vol. 2, no. 2, pp. 113-127, May 2017, doi: 10.1016/j.idm.2017.02.001.

[30] K. Ameri and K. D. Cooper, "A Network-Based Compartmental Model For The Spread Of Whooping Cough In Nebraska.," AMIA Jt. Summits Transl. Sci. proceedings. AMIA Jt. Summits Transl. Sci., vol. 2019, pp. 388-397, 2019, [Online]. Available: http://www.ncbi.nlm.nih.gov/pubmed/31258992.

[31] W. O. Kermack and A. G. McKendrick, "Contributions to the mathematical theory of epidemics-I," Bull. Math. Biol., vol. 53, no. 1-2, pp. 33-55, Mar. 1991, doi: 10.1007/BF02464423.

[32] M. Bhattacharjee and A. Bose, "Modelling COVID-19 -- I A dynamic SIR(D) with application to Indian data," Sep. 2020, [Online]. Available: http://arxiv.org/abs/2009.05044.

[33] B. J. Rami Krispin, “'Package "coronavirus,"'” 2020. [Online]. Available: https://github.com/RamiKrispin/coronavirus. 


\section{Figures}

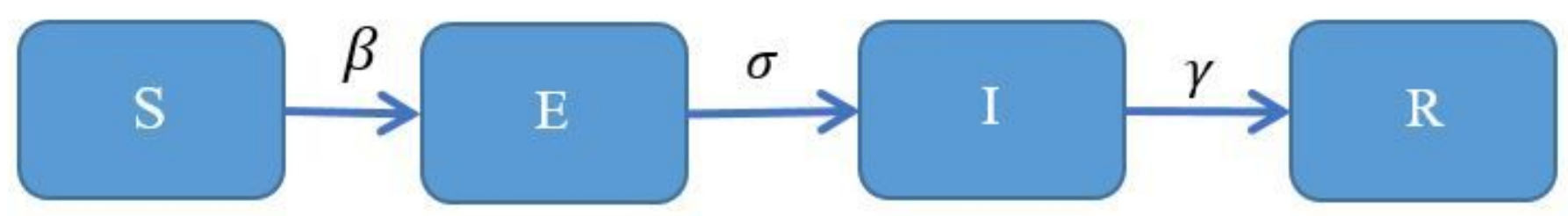

Figure 1

The generic SEIR model.

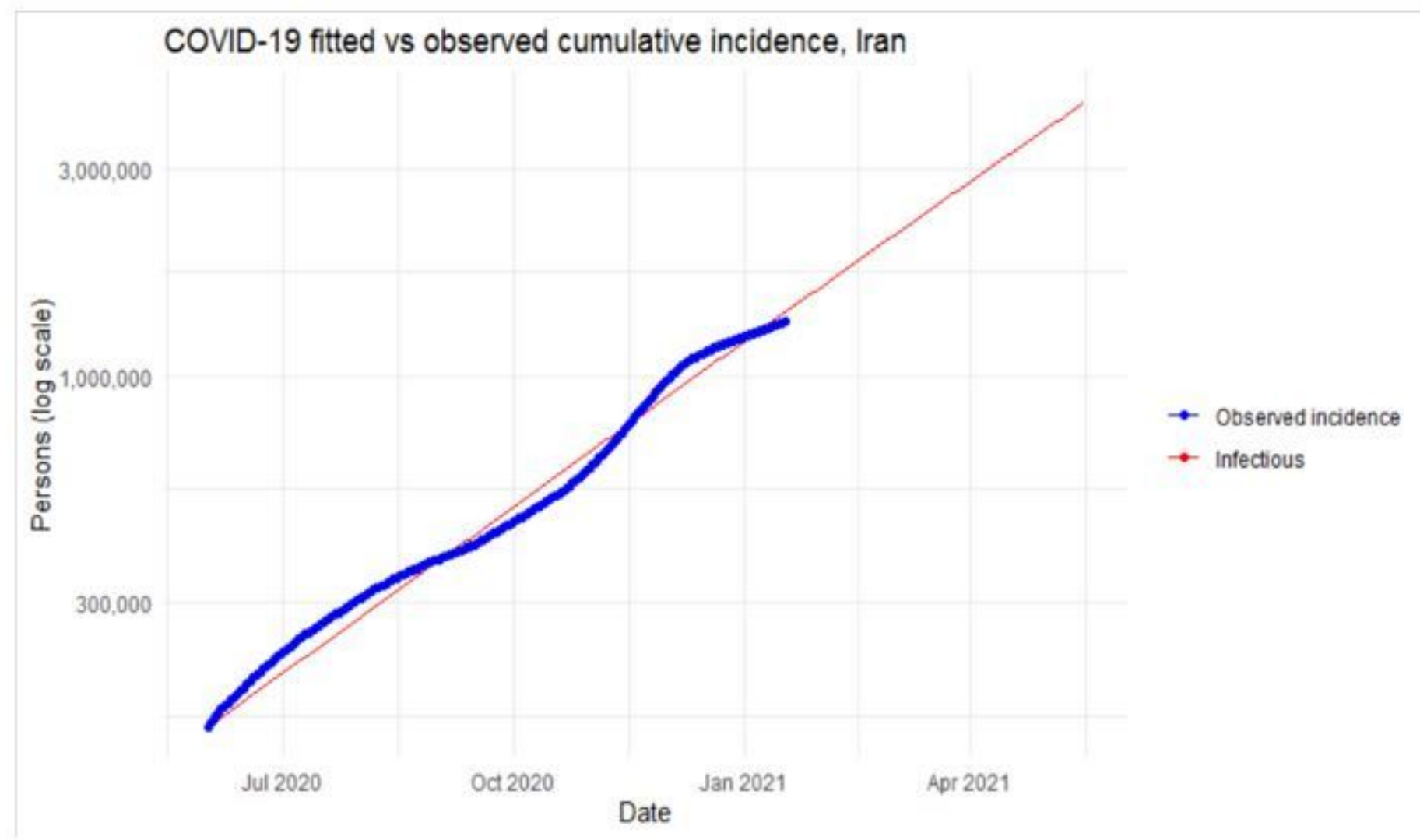

Figure 2

fitted model 
Daily Covid-19 Cases

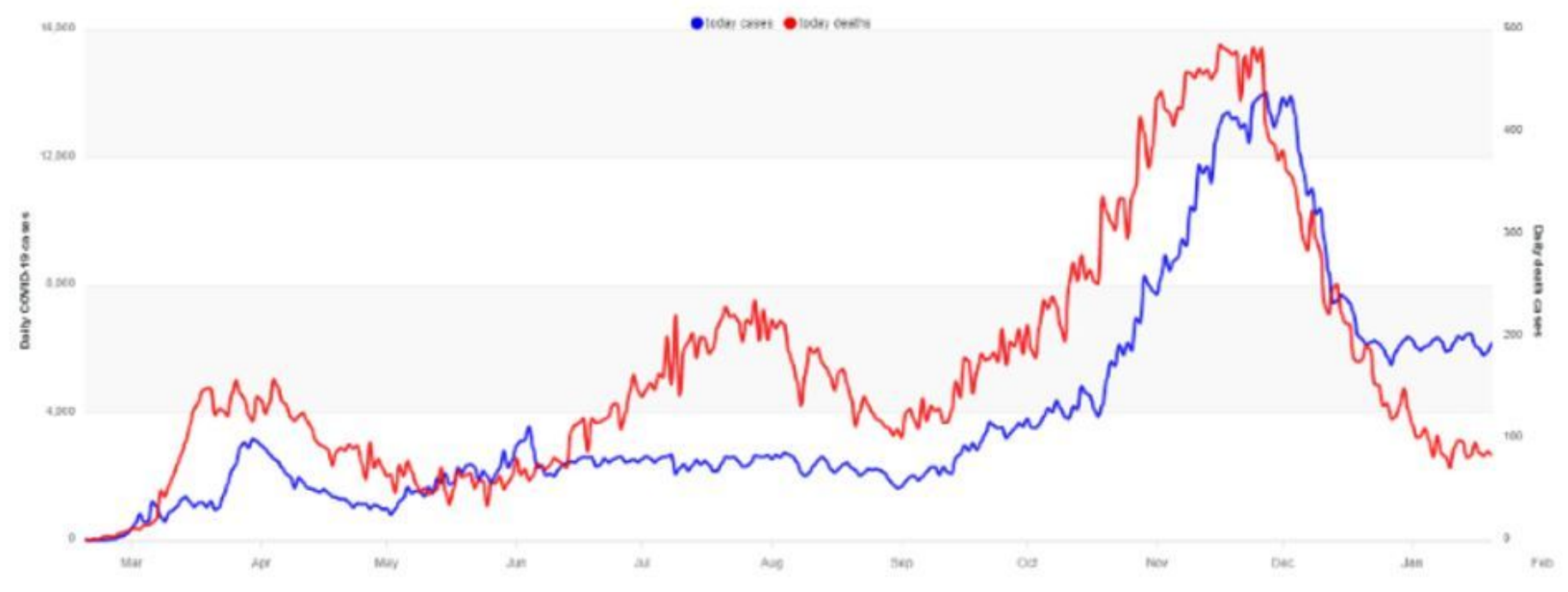

Figure 3

Daily COVID-19 cases and death of Iran

The Next Peak of Infected Individuals, Iran

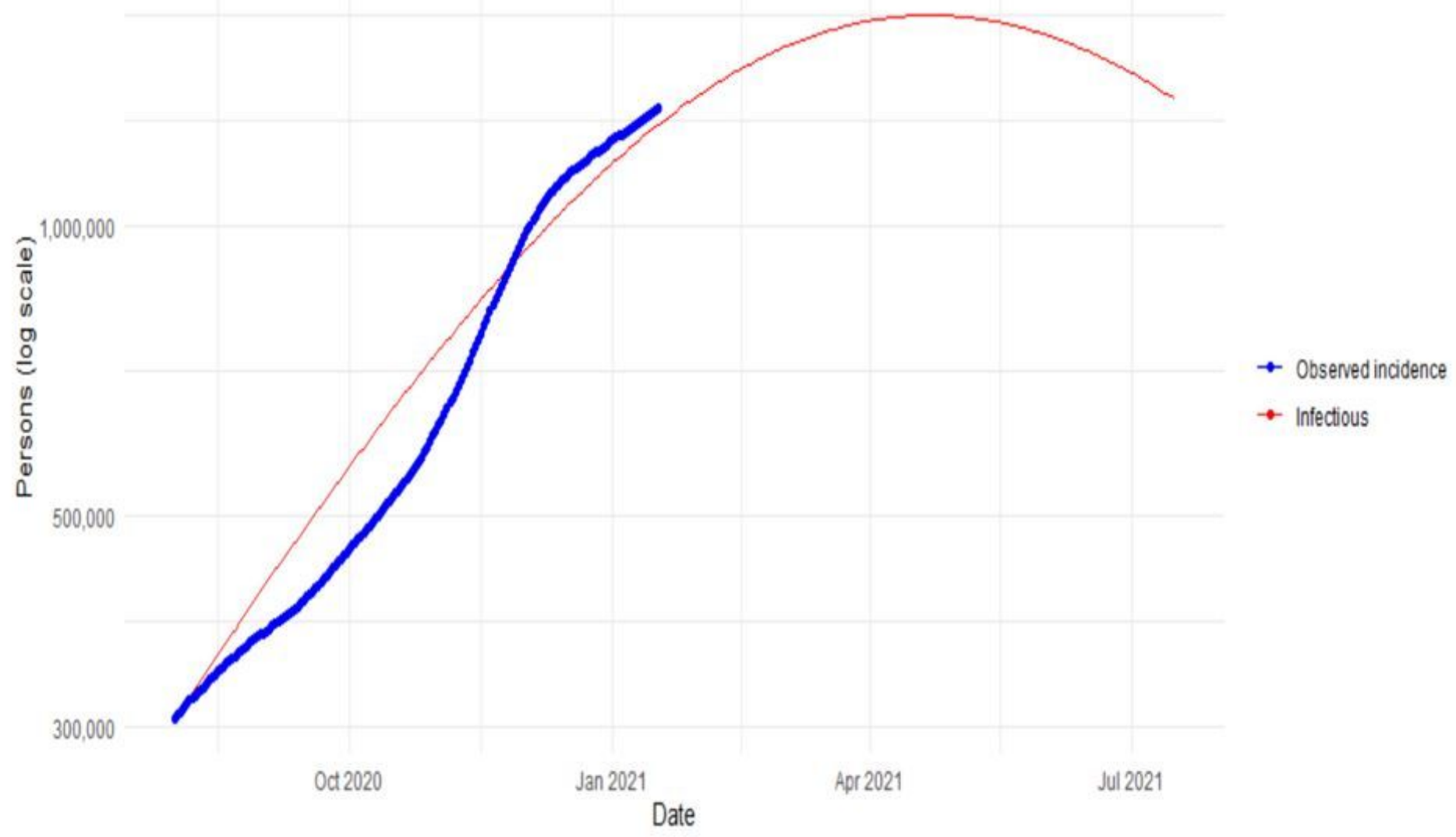

Figure 4 
Prediction the next peak

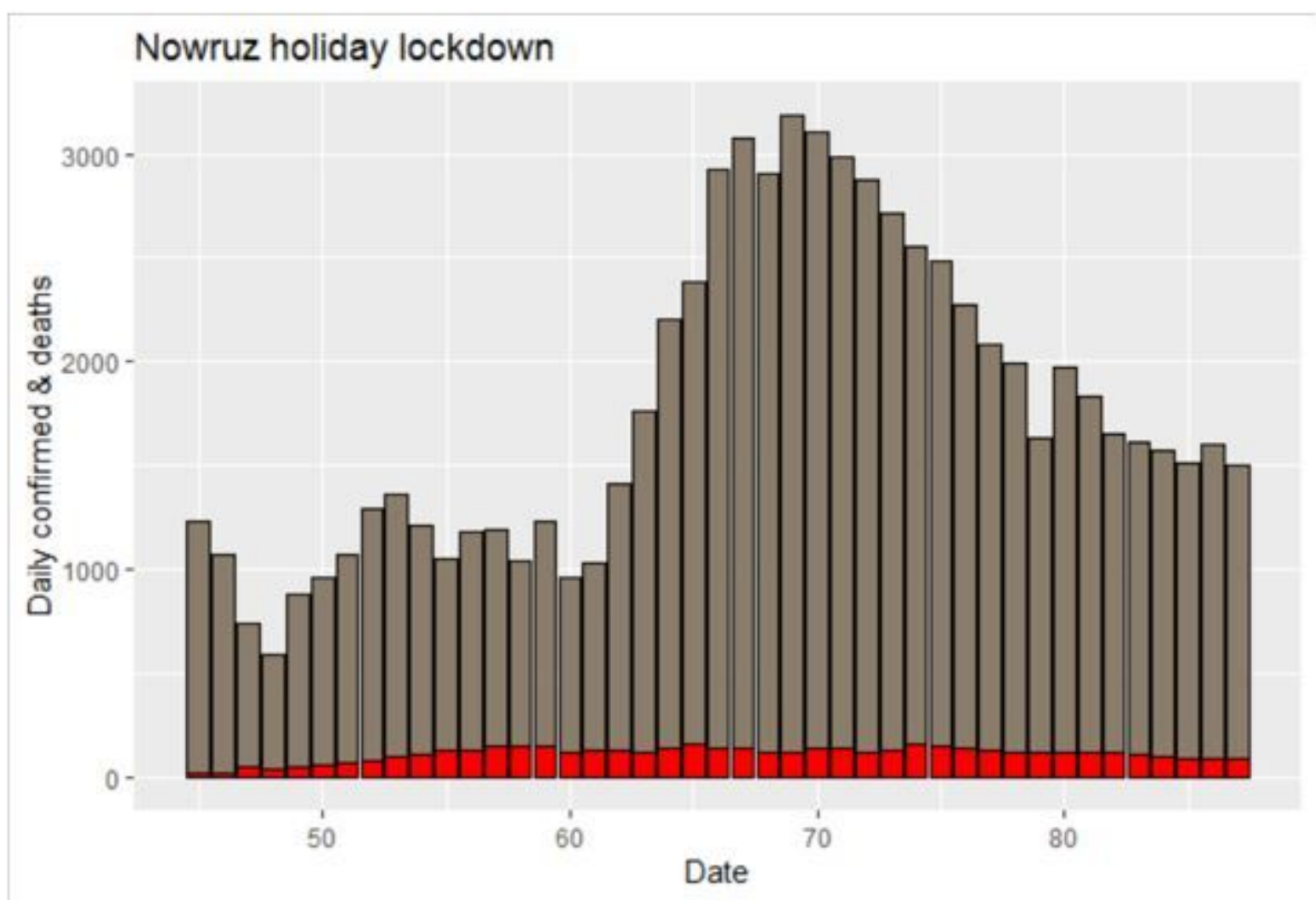

Figure 5

Nowruz holiday lockdown 


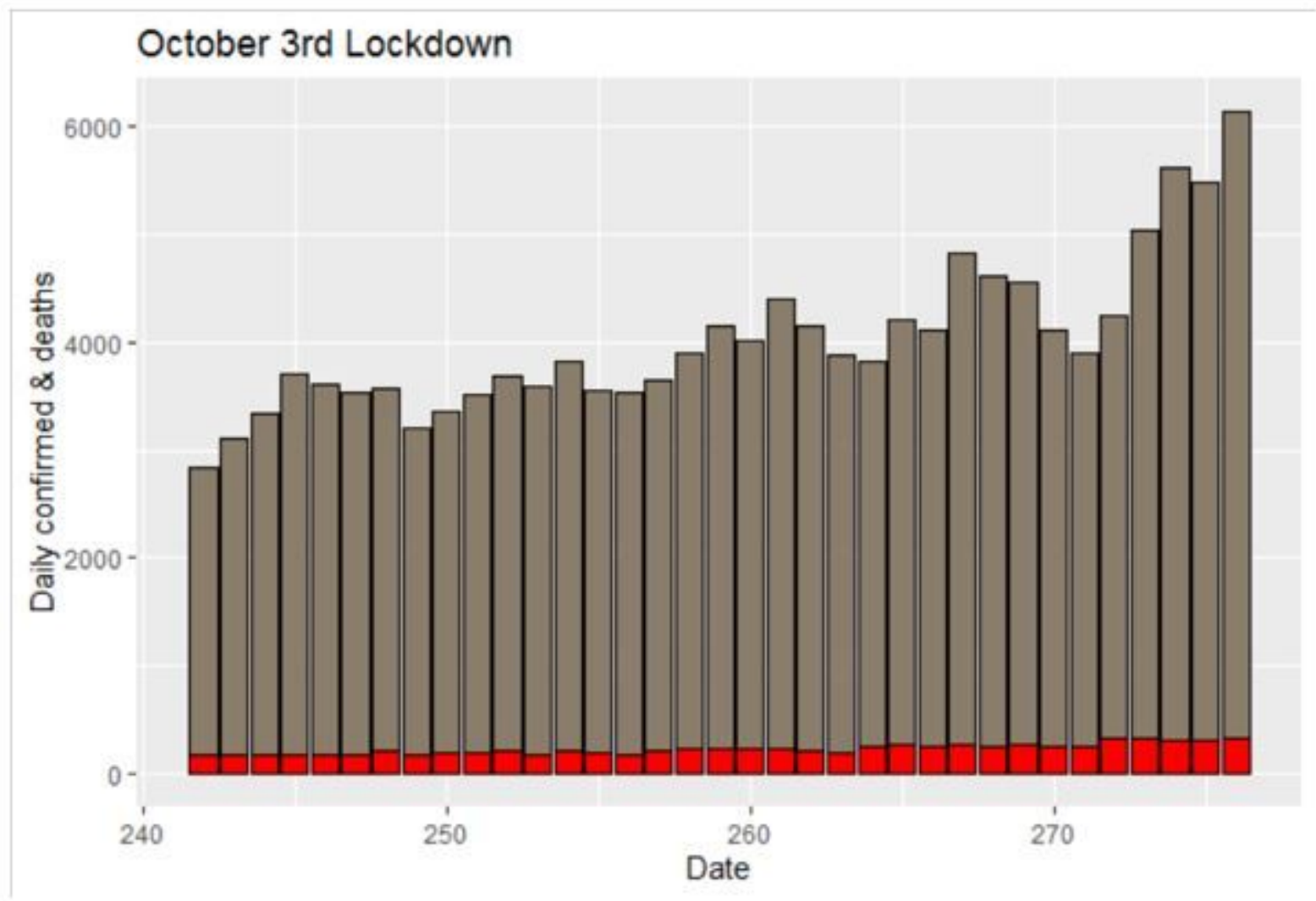

Figure 6

October 3rd Lockdown 


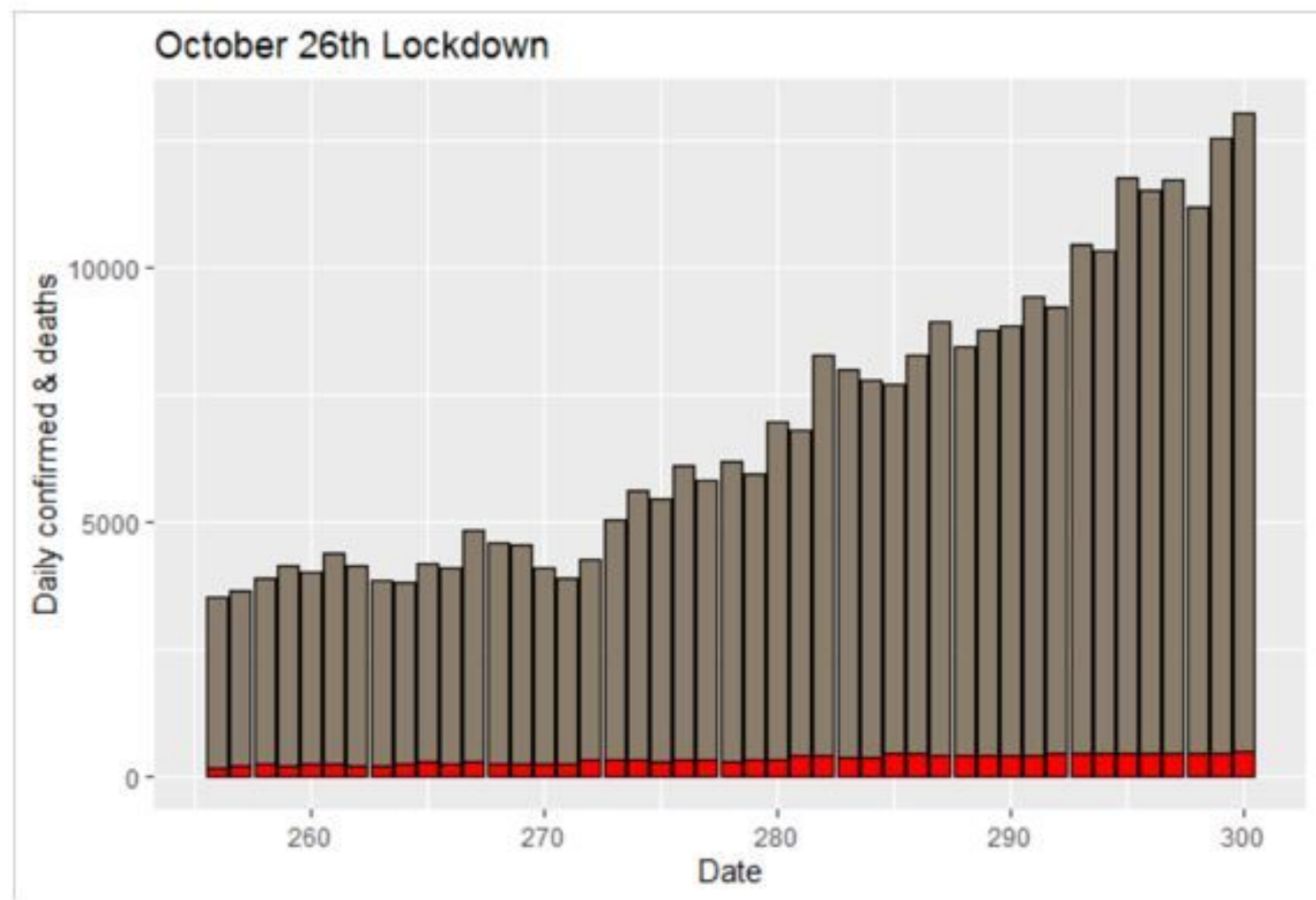

Figure 7

October 26th Lockdown

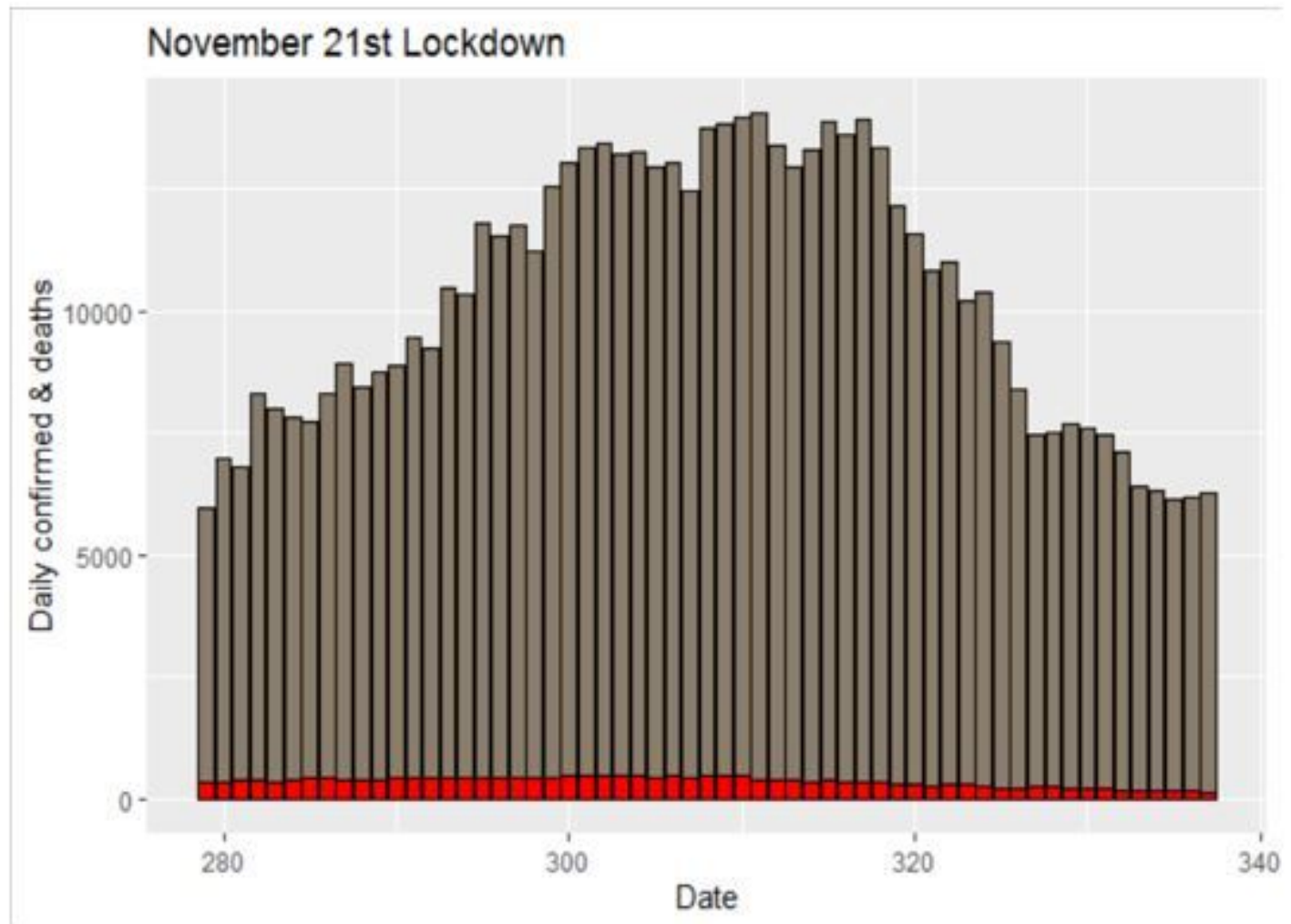


Figure 8

November 21st Lockdown

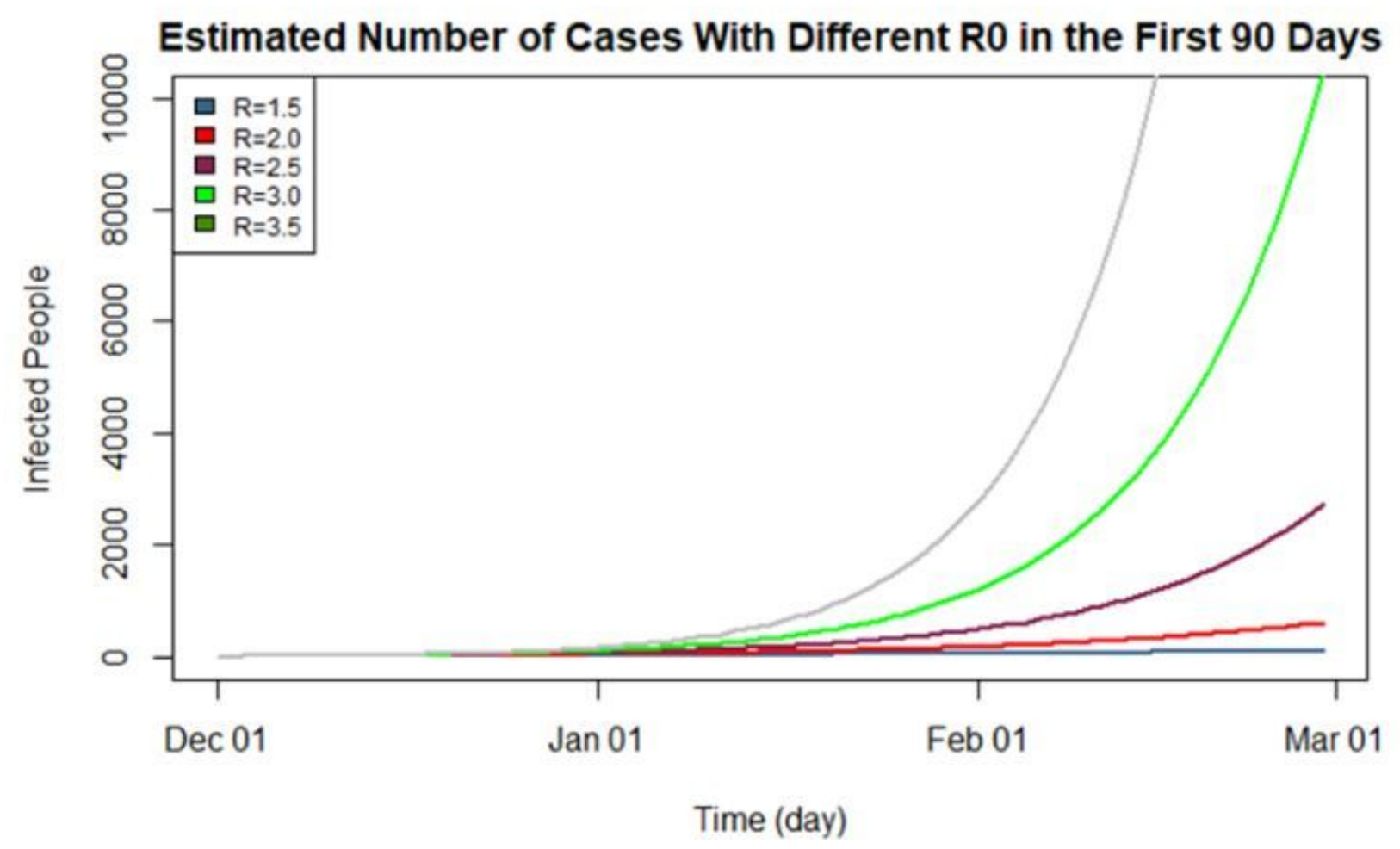

Figure 9

estimated number of cases with different R0 


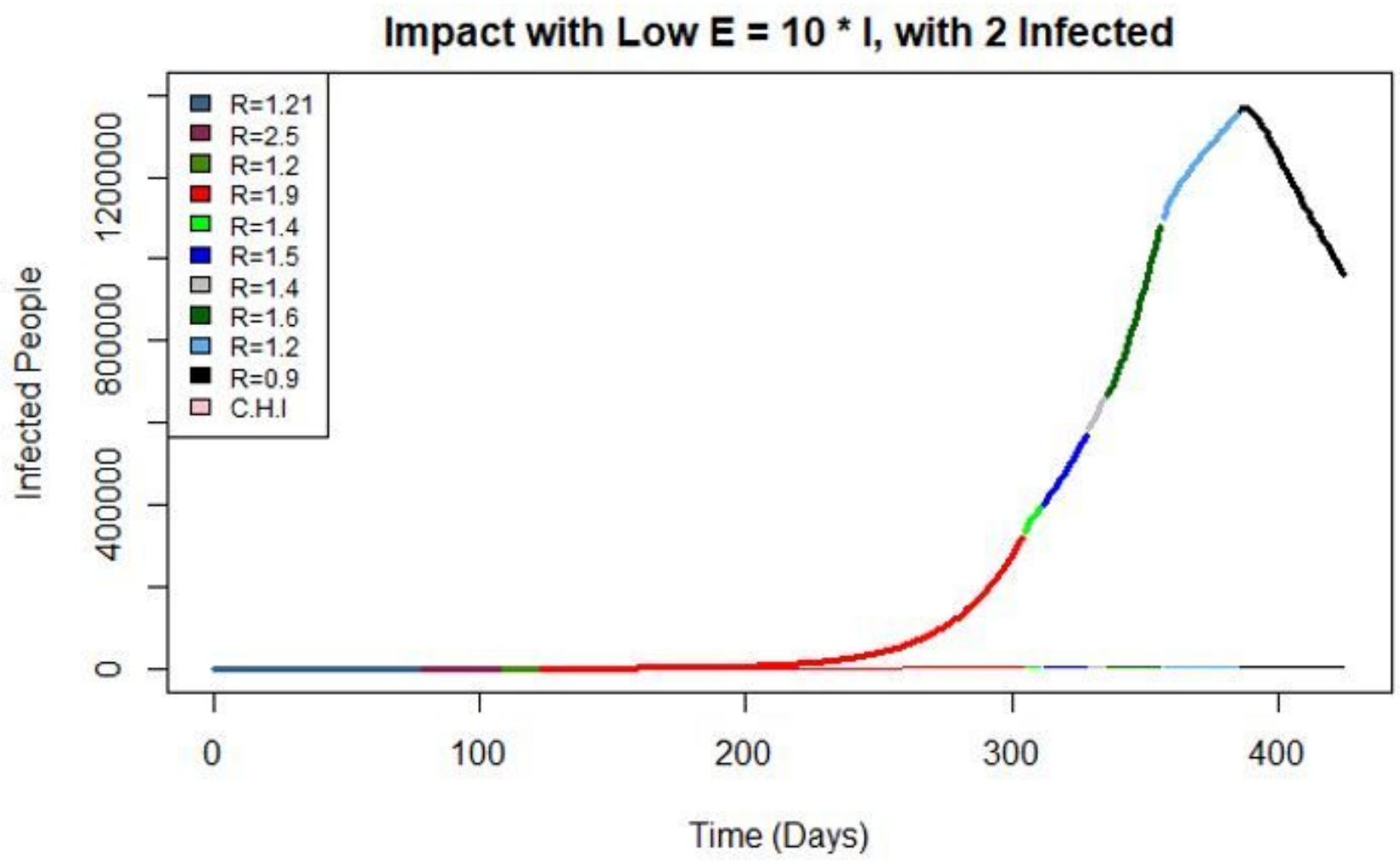

Figure 10

Impact of government interventions under the Low E assumption. 


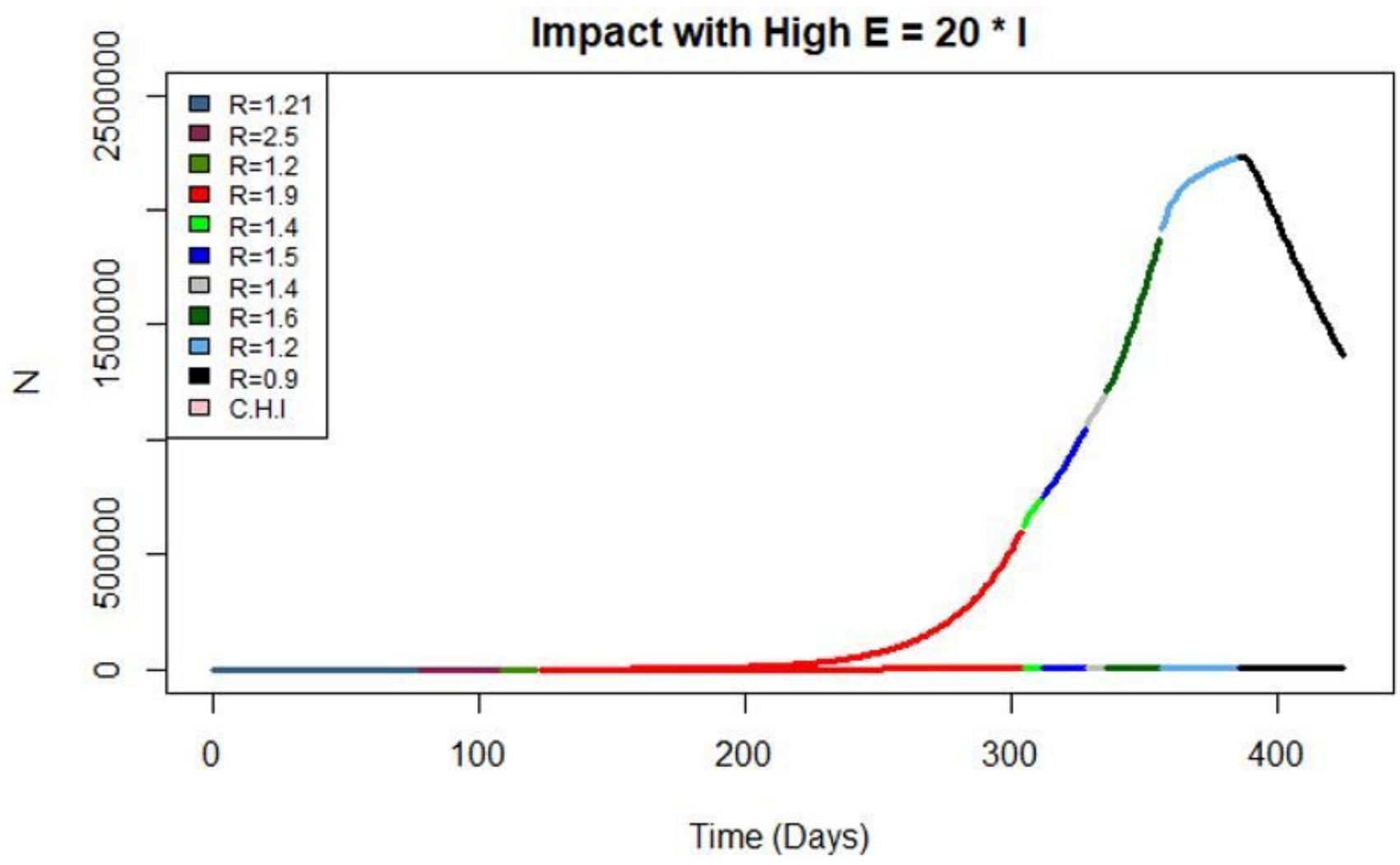

Figure 11

Impact of government interventions under the High E assumption. 